\title{
Disparaging Wives Through Humor: A Linguistic Analysis Of Jokes On Pakistani Social Media
}

\author{
Ammara Iqbal \\ Department of English \\ University of Sargodha
}

\author{
Muhammad Asim Mahmood \\ Faculty of Arts and Social Sciences \\ Government College University Faisalabad
}

\author{
Musarrat Azher \\ Department of English \\ University of Sargodha
}

\begin{abstract}
Humour is a tool to develop and to strengthen mutual relationships among people. Humour sometimes is used to show superiority of a person, sect, caste or gender to other. This particular study about the linguistic structure of randomly selected jokes is made in order to highlight different stereotypes that are associated with the Pakistani wives. For this purpose, a corpus of 60 jokes is developed by collecting jokes randomly in Urdu language related to wives, using two facebook pages, "Husband \& Wife jokes" and "Laughing colours" and then twenty jokes are further selected under specific themes for analysis. These jokes are translated into English language and then analysed using the Atordo's \& Raskin's model of (GTVH) general theory of verbal humour (1991). This study also throws light on the fact that the stigmas attached with Pakistani wives in the form of jokes are widely accepted and enjoyed even by wives themselves that is giving way to their disparaged identity in our society. Hence, aim of this study is to make the Pakistani women and the wives aware of the intensity of this situation and to provoke them to reject this practice of their disrespect and exploitation through verbal humour. This study will also prove helpful for the future research in order to observe this prejudiced activity on a wider scale and to oppose it to make variations in the attitude of the participants and the receivers of the jokes to discourage jokes which are the source of disrespect for any other sect or gender.
\end{abstract}

Keywords: Humour, Wives in Jokes, Stereotypes, Disrespect and Exploitation

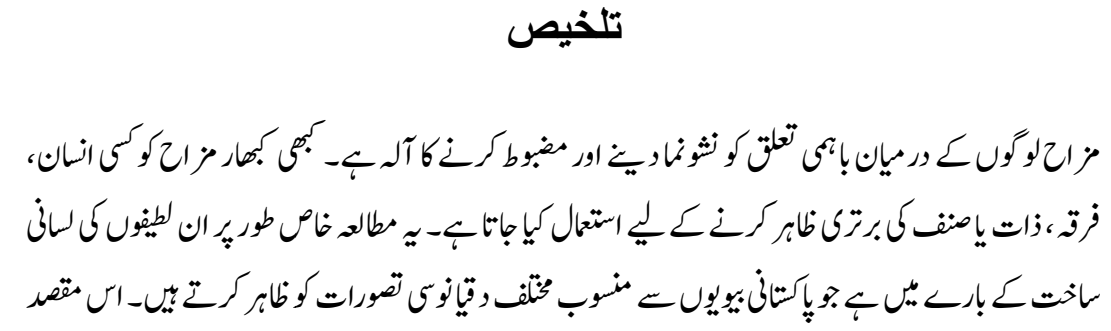




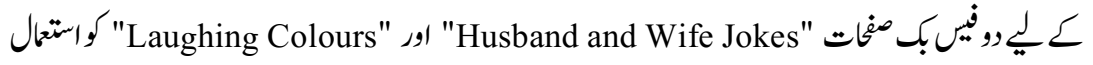

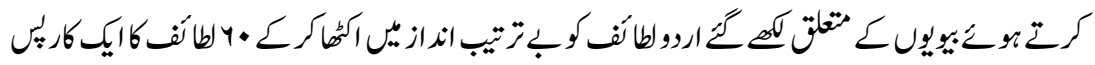

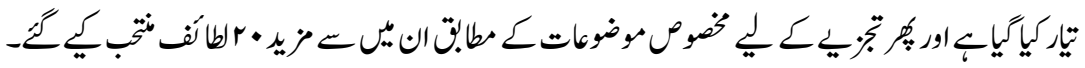

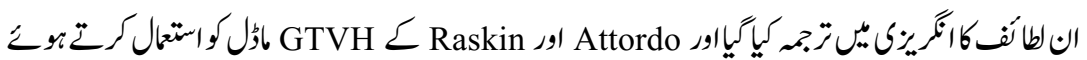

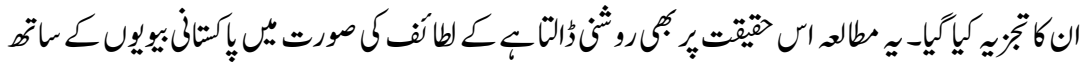

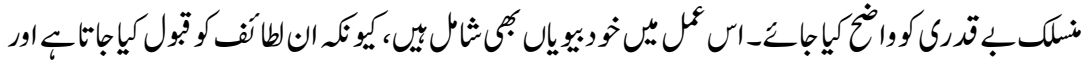

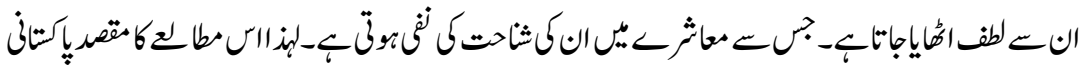

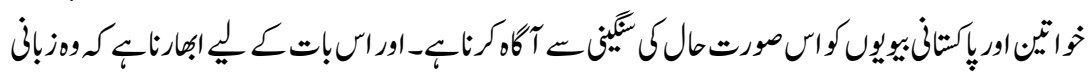

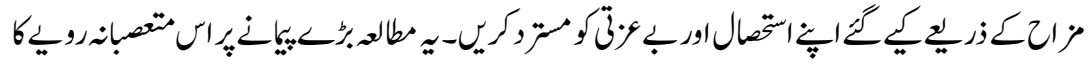

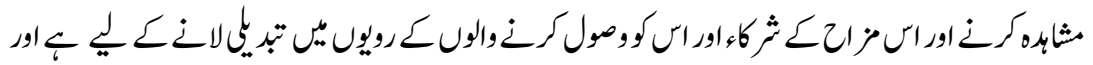

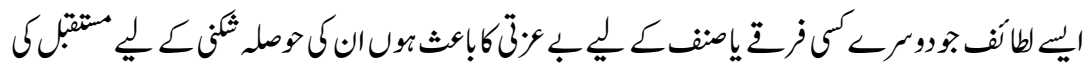

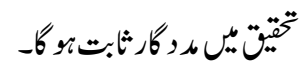

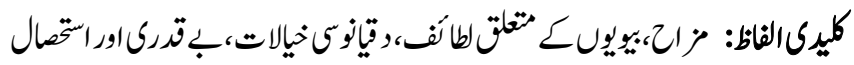

\section{Introduction}

Humour helps people make their relations strong and create a feeling of intimacy. Humor in our society with achieving other aims, is also giving way to certain stereotypes which most of the times are the result of exaggeration and false reasoning. Humor most oftenly is targeting women and their role in society and creating gender stereotypes. Various researchers have studied the effects of social context, class system, and ethnicity on humor.

Humor most of the times disparages others in which the target is victimized and faces misfortune or aggression (Zillmann, 1983). The disparaging humor may target a specific individual or a particular social group. This kind of humor is considered as a source of enjoyment by the researchers. Freud (1905/1960) argued about the enjoyment of such humor that people find disparaging humor as amusing because it helps express the aggressive and hostile feelings in an acceptable way. This idea is similar to Zillmann \& Cantor's (1976, pp. 93-115) dispositional theory of disparagement humor which considers that if people are having negative, positive or both attitudes toward a victimized group, they will enjoy this particular disparaging humor. Various researchers have studied the effects of humour in generating stereotypes including gender, races and class. Gregory proposes that disparagement humor produces negative stereotypes. Such humor causes joke tellers to develop more negative stereotypes of the disparaged 
or victimized group. This humor permits the expression of negative sentiments toward a target in a socially acceptable way hence, enjoyable. Recitation of humor also causes to develop negative stereotypes as Gregory \&James M. Olson \& Jacqueline E. Bush, have the view that "reciting disparaging humor causes joke tellers to develop more negative stereotypes of the disparaged group" (2016, pp.1986).

This particular study discusses and analyzes jokes involving wives as their target. These jokes are analyzed using Attardo \& Raskin's theory of verbal humor (GTVH). According to this theory, humour in a joke is created through incongruity which according to Agnieszka, is a clash between various frames, expectations or scenarios, and to create a humorous effect it has to be resolved. Agnieszka considers the superiority theory of Aristotle saying that humans take a delight in mocking others over their misfortunes because it makes people feel superior (Agnieszka Piskorska, 2016). Aim of this particular study is to analyze.

1. What are the linguistic features of the jokes which are helping these jokes convey their meanings?

2. How jokes on wives are creating and promoting stereotypes about them?

\section{Review of Literature}

Humor works as a connector between individuals in a social setting. Humor owing to its rewarding nature, provokes people to make further humorous practices during their conversations. Ervin et al., (1992) presented that laughter is rewarding enough to make people produce jokes and use humor to spread laughter. Participants of humor may have different constructions in their conscious subconscious, that make them show their stereotypical and prejudiced attitude in a lighter way under the guise of humor that unconsciously make their stereotypical structures more vigorous.

Humorous practices vary with respect to ethnicity, gender, groups and other social constructions (Ervin-Tripp \& Lampert, 1991; Lampert \& Ervin-Tripp, 1989). Men's self directed humour unlike of women's, can be characterized as more defensive, involving more exaggeration and less evoking of shared experience. "The men's self-directed humor turned out to be somewhat different in character from the women's, involving more exaggeration, more provocation, and less evoking of shared experience"(Ervin-Tripp, 1984).

Lee Jenkins made observations about gender differences and humorous talk at a Berkeley conference on women's language. He found that women's humor more often involved reinterpreting negative experiences, less often performance-based, 
and was more context-bound in comparison with the men's humor (Jenkins, 1985).

On the other hand, a shift in the humorous strategies of males and female participants is also observed in some studies. Ervin et al., (1992) observed white males and females' shift in their strategies when they join in gendered homogeneous and gendered mixed group settings. In mixed gender group settings, women show decrease in their self-directed humor. Men on the other hand use self-directed humor that involves more exaggeration and provocation less while evoking of shared experiences is less prominent in men's humor.

Lampert \& Ervin-Tripp (1998, pp. 231-270) studied effects of gender and ethnicity on humor in natural conversations as they consider social context, a strong force behind the produced form of humor. Humor plays prominent role in displaying inner feelings of participants towards others.

Many studies have been made to observe females' humor and it has been observed that women use humor which displays their cooperative practices and reinforcement of solidarity. Acuna Ferreira (2014) studied formal and functional characteristics of female humor during their spontaneous conversation through analyzing the two extracts of gossip between two female Galician students. Various studies show that females oftenly use affinitive humour and self directed humor while males use aggressive humor more prominently.

People generally use humour in order to give vent to their feelings without any fear. Green (1977, pp.29-33) studied the humor of a speech community of US southern white women and collected most of the examples at a family gathering. He makes a speculation that the women in this speech community were using humor as a tool to give vent to their feelings. They also included children in the circle of their audience in order to take revenge from their men through humor, because they were controlling their lives. It is observed by the researchers that a change is witnessed in the attitudes of the listeners toward the acceptance of the anti-female humor through years. Lampert \& Ervin-Tripp (1998, pp.231-270) reviewed certain studies conducted from 1970 to 1996 in order to notice the variations in the attitudes of the audience towards the acceptance of anti-feminist humor. They observed a decline through years in the acceptance of anti-female humor by the audience. Rather the emergence of humor that is targeting socially constructed male attitudes is getting prominence.

Pakistani society on the other hand is producing as well as promoting humor that targets women's roles more prominently especially the role of women as wives. These jokes present women differently in their changing roles. Jokes about unmarried women show them as unintelligent, beauty conscious, dependent, 
talkative and weak while jokes about married women most of the times present them as talkative, clever, authoritative and violent creatures. This change portrayed through jokes about women is quite strange.

Males play different roles in society hence enjoying different status than females. In this way, their talk is also different from talk of females. "Men are from Mars, women are from Venus" (Gray, 1992). Men produce humor in order to marginalize women in society and they use to mock their wives' role in society. Some are producing humor through exaggeration, making false reasoning, false analogies and through exploiting various linguistic features. Women as wives are being marginalized through humor. They are considered worthless, unintelligent and unreasonable. Joke tellers are marginalizing and victimizing women to disparage their identity by generating and further promoting humor. A very rare study is made on this issue in Pakistan. Saira Rashad \& Musarrat Azher (2018) in their article related to women in jokes, described that creating stereotypes about women through jokes is a tool "which eventually culminates into social injustice directed upon women" (pp. 14).

Humor produced by male and female participants can be analyzed by using different frameworks which helps to analyze the semantic meaning of descriptive humor. Raskin et al., (2009) discussed theories of humor and their linguistic frameworks to study humor. They discussed the evolution of SSTH into GTVH and their importance in the analysis of descriptive humor though observing linguistic features. They also discussed knowledge resources of General Theory of Verbal Humor in order to present a framework for analysis of humor and provoke researchers to analyze humorous practices more explicitly.

Attardo et al., (2002) displayed the survey of all familiar logical mechanisms. They used different theories and explored the ways of representing the different concepts of GTVH (General theory of verbal humor). Knowledge resources of GTVH helps to linguistically analyze the target of the humor and the hidden stereotypical and prejudiced practices of the participants of humor. Linguistic framework presented by GTVH (General theory of verbal humor) has helped the researchers to observe the attitudes of different social groups to one another which include genders, castes, social classes, ethnic groups, and sometimes nationality.

\section{Theoretical Framework}

This particular study of the selected jokes is made by using the framework of Raskin's \& Attardo's (1991) theory, Gereral Theory of Verbal Humor (GTVH). Twenty jokes have been selected from facebook pages, "Husband \& Wife jokes" and "Laughing Colours", using Pakistani social media which are creating and promoting stereotypes about wives regarding their intellect, ugliness, authoritative, talkative 
and their violent behaviour. Four jokes lie under each category. These jokes then translated from Urdu language to English and analyzed on the basis of six knowledge resources of GTVH which are (i) Script Opposition, (ii) Logical Mechanism, (iii) Situation, (iv) Target, (v) Narrative Strategy, and (vi) Language. Selected jokes have been translated from Urdu language to English therefore, humor of these jokes is generated through their content instead of their linguistic manipulation or exploitation.

\section{General Theory of Verbal Humor (GTVH)}

General Theory of Verbal Humour (GTVH) is given by Victor Raskin and Salvatore Attardo gave in their article "Script theory revised: joke similarity and joke representation model" (Raskin \& Attardo (1991, pp.293-347). GTVH included Script Opposition (SO), as one of six levels of independent Knowledge Resources (KRs) given below that were previously discussed by Raskin in his Script-based Semantic Theory of Humour [SSTH] (Lew, 1996). Following are the six knowledge resources of GTVH.

\section{Script Opposition (SO)}

This knowledge was previously developed by Raskin's SSTH. It involves two opposing scripts that make their presence in all humorous texts. This is considered the most abstract KR among all others. Oring (1992) has discussed that Script Opposition is a formalized version of incongruity and this incongruity needs to be resolved in order to make a text humorous.

\section{Logical mechanism (LM)}

Knowledge resource of logical mechanism describes the ways in which hidden script is brought to the surface and incongruity generated in SO is resolved. This incongruity has to be resolved in order to make a text funny otherwise it turns into a riddle (Oring's theory 1992, 2003).

\section{Situation (SI)}

Every joke or humorous text should have some situation or props, which can be the objects, participants, activities, Instruments, etc. Some jokes can also exist without them according to their narrative techniques and content.

\section{Target (TA)}

The knowledge resource of target is also considered as the butt of the joke. It targets a particular gender, sect, caste, etc. This category also helps in creating and promoting stereotypes (Masaeli \& Heidari-Shahreza, 2016, pp.230-239). 


\section{Narrative Strategy (NS)}

It deals with the format of the narrative of a joke, whether it is in the form of a dialogue, simple narrative, riddle or it is in question and answer format.

\section{Language (LA)}

This knowledge resource contains all the information that is necessary to verbalize a text. LA includes all the linguistic components of a particular text.

\section{Methodology}

This study consists of a primary research in which data is collected through social media application. Facebook is used as a medium to collect data. A corpus of 60 jokes related to wives is developed by using two facebook pages, "Husband \& Wife jokes" and "Laughing colours". All of these jokes were in Urdu language which was translated in English and then these related to wives, using two facebook pages, "Husband \& Wife jokes" and "Laughing colours" and then twenty jokes are further selected on the basis of their relevancy to the five selected themes for analysis. These themes are, Wives as Talkative Creatures, Wives as Violent and Troublesome Creatures, Wives as authoritative creatures: Wife, a stupid creature, and Wives as bad and ugly creatures respectively. Four jokes are placed under each category to observe coherence. Later on these selected jokes are translated into English language and then analysed using the Atordo's and Raskin's model of (GTVH) general theory of verbal humour(1991).

\section{Analysis and Discussion}

Selected jokes are divided in five categories, each containing four jokes, on the basis of different stereotypes associated with the wives. These categories and analysis of the jokes under them, are given bellow.

\section{Wives as Talkative Creatures}

Following are the jokes in which wives are presented as nonstop talkers who are unbearable for their husbands and they talk without even using their intellect.

\section{Joke: 01}

Shohar: Judge sahib mujhy talaaq chahiye. Meri bivi ny mery say aik saal say baat nahi ki.

(Husband: Respected Judge I want divorce. My wife hasn't talked to me for a year.) 
Judge sahib: Aik bar phir sy soch lo aysi bivi sirf qismat walon ko milti hy. (Respected Judge: Think on it once again, only fortunate people have this kind of wife.)

\section{Analysis}

So in this joke is talkative/silent woman and the additional script opposition is lucky/unlucky person. Incongruity introduced in SO is resolved in the logical mechanism of exaggeration when the judge asks the person to think once again as only lucky persons have such kind of silent women. Situation in this particular joke is that a person is standing before a judge in the court and wants to divorce his wife because his wife has not talked to me for a year. This joke is in the form of a simple narrative which consists of a dialogue between two persons a husband and a judge. Butt of the joke are the talkative women who are considered as a sign of bad luck for the husbands. Language of the joke is simple and adjective of fortunate person is used in the punch line which is generating humour in the joke.

\section{Joke: 02}

Choty hoty ammi say sunty thy $\mathrm{k}$ "agar maindak ko pathar maara tou bivi goongi mila ygi".

(In the childhood it was heard from our mother, "if you hit a frog with a stone you would find a dumb wife")

Ab sochty hain $\mathrm{k}$ kaash maar hi diyahota. (Now i aspire, would that I had done that)

\section{Analysis}

In this joke So is talkative/silent woman and the additional SO is possibility/ impossibility and this incongruity which is introduced in SO is resolved in the logical mechanism of faulty reasoning which describes that if one hits a frog in the childhood with a stone, he will find a dumb wife in future. Situation is that a person is recalling his childhood and his mother's statement. Target of the joke are the women as they are considered talkative to a dreadful extent that they are preferred by the males to be dumb. NS of this joke is in the form of a monologue and its language is simple. Adjective of "dumb wife" is used in the first sentence. While second sentence works as a punch line as it creates humor. This punch line seems to be uttered in low pitched sound that is heightening the effect of the joke.

\section{Joke: 03}

Hmari zubaan ko maadri zubaan iss liye kaha jata hy kun kay..... baap ko bolny ka moqa hi nai milta 
(Our language is called mother tongue because....... Fathers don't get any chance to use his tongue (speak a language))

\section{Analysis}

Script Opposition in the joke is talkative/silent wife and the additional SO is factual/unfactual. Incongruity of the joke is resolved in the logical mechanism of faulty reasoning that a language is called mother tongue because father don't get a chance to use their tongue and to speak language. Exaggeration is also used as LM of the joke. Situation in the joke is not mentioned in the joke. Target of the joke are the wives who talk so much that they don't give their husbands a chance to speak. This joke is in the form of a single sentence and its narrative is simple. First part of the joke attracts our attention and raises a question while the second part solves that riddle in a ridiculous way that creates humor.

\section{Joke: 04}

Shohar ny chewing gum khareed kar bivi ko khany kay liye di (Husband bought his wife a chewing gum to eat)

Bivi: Aap ny apny liye kun nhi li?

(Wife: Why didn't you buy it for yourself?)

Shohar: Main tou is ky bagair hi khamosh reh sakta hun.

(Husband: I can remain quite without it....)

\section{Analysis}

In this joke SO is talkative/silent wife and the additional SO is possibility/ impossibility and the incongruity is in the logical mechanism of exaggeration that by chewing a chewing gum makes a wife silent. Situation in the joke gives a clue that husband and wife are outside and they are at some shop or grocery store from where husband buys his wife a chewing gum. Target of the joke are the wives as they are considered as the creatures who can't stop talking. NS of the joke is in dialogue form and simple language is used in the sentences. First two sentences are simple while third sentence is in the form of a question which answer is given in the final or the punch line that creates humor in the joke.

\section{Wives as Violent and Troublesome Creatures}

In the jokes under this category, wives are presented as the violent and troublesome creatures who sometimes even thrash their husbands.

\section{Joke: 01}

Sawaal: Susral ma daamaad ki izzat kun ki jati hy?

(Question: Why the son-in-law is respected in his in-laws?) 
Jawab: Kunky wo janty hain k yahi wo azeem insaan hy jisny hamary ghar kaay toofaan ko sambhaal rakha hy.

(Answer: Because they know that he is the great man who is having the storm of their house).

\section{Analysis}

$\mathrm{SO}$ in this joke is troublesome/obedient wives and the additional SO is normal/ abnormal woman. Incongruity which is introduced in SO is resolved in the logical mechanism of faulty reasoning which describes that son-in-law receives respect in his in-laws because he is taking care of the storm of their house (their daughter). Situation (SI) is not mentioned clearly. Perhaps two people are indulged in the dialogue. Target or butt of the joke are the women who are considered troublesome and unbearable for even her family. Narrative of this joke is in the form of a dialogue in the question answer format. Language of the joke is simple. It has an adjective of "great man" which is used for the son-in-law in order to consider his power to bear their stormy daughter. This adjective points to the height of abnormality in the wives and this last line which is also called a punch line, creates humor.

\section{Joke: 02}

Agar glass tootny kay baad bhi ghar ma khamoshi rahy tou.. (If there is silence in the house after breaking of the glass then......)

Glass zarur bivi say toota hy aur... ghalti bhi glass ki hy. (Then surely it is broken by the wife and... the mistake is also of the glass.)

\section{Analysis}

Script opposition in this joke is violent/nonviolent wives and the additional SO is clever/innocent wives. Incongruity in $\mathrm{SO}$ is resolved by exaggeration as the logical mechanism which presents that women are unjust and clever as when they break a glass they don't make noise and don't accept their mistake. In this joke situation (SI) is not mentioned explicitly. Target of this joke are the unjust and clever attitude of the women over doing a mistake (breaking of a glass in the joke). This joke is in the form of a declarative statement containing inferring consequences. Language of the joke is simple. First sentence presents a consequence of some action while in the second statement the information about the action of cause of that consequence is described which also behaves as a punch line of the joke and which is responsible for the humor in the joke

\section{Joke: 03}

Doctor: Ap ky teen daant kesy toot gaye?

(Doctor: How did you get your three teeth broken?) 
Mareez: Ji wo meri bivi nay karak roti banai thi.

(Patient: Sir my wife made a...... bread

Doctor: tou khaany say inkaar kar daity.

(Doctor: Then you should have refused to eat it.)

Mareez: Ji wohi tou kiya tha.

(Patient: Sir, I did the same.)

\section{Analysis}

$\mathrm{SO}$ of this joke is expert/ amateur wives and additional SO is violent/non violent wives. Incongruity generated in SO is resolved by using LM of exaggeration and false reasoning through which an impression is generated that wife of the person broke his teeth on refusing to eat the bread made by his wife. SI in this joke is that a patient goes to a dentist after getting his three teeth broken. Narrative of this joke is in question and answer format and in the form of a dialogue. This dialogue goes between a doctor and a patient. Riddle created in the joke is solved in the last line of the joke which is the punch line that is the source of creating humor in the joke.

\section{Joke: 04}

Mian bivi aik restaurant ma khana khanay gaye.

(A husband and wife went to a restaurant for a dinner.)

Mian aaspaas baithi aurton ko dykhnay laga.

(Husband started to stare at the women sitting around.)

Bivi ny poory zor sy shohar ky mun py thappar maar dia.

(The wife slapped his husband in his face with full strength.)

Iss par shohar ny maasoomana andaz ma bola, "ma dieting par hun is ka matlab ye nahi kay ma khany ko daikh bhi nai sakta".

(On this, the husband uttered innocently, "I am following a diet plan, it doesn't mean that I can't even stare at the food.)

\section{Analysis}

$\mathrm{SO}$ in this joke is violent/nonviolent wives and its additional SO are animate/ inanimate objects and civilized/uncivilized wives. Incongruity of the joke is resolved through the LM false analogy and faulty reasoning. The husband's staring at the women is compared with his staring at the food. Reasoning and the analogy presented is falslywoves as women are animate while food is inanimate. Exaggeration is also used in the joke as a wife is presented as so violent that she slaps her husband's face even on a public place. This exaggeration presents wives as uncivilized and violent creatures. SI of the joke is that a husband and wife are at some restaurant and husband is quite and staring at other women. SO of the violent wives suggest that the target of the joke are wives. This joke is in 
the form of simple statements except the last statement which is an assertive statement that is made by the husband. This last line which is in the form of a pun, excites humor.

\section{Wives as Authoritative Creatures:}

In the following jokes, wives are presented as authoritative individuals and it is presented that husbands are helpless before their wives and they are unable to make their decisions freely and independently. In these jokes wives are the sole authority at home.

\section{Joke: 01}

Gussy ka aana mard hony ki nishaani hy.

(To become angry is the quality of a male.)

Aur gussy ka pee jana ....

(And to gulp the anger....)

Shadi shuda mard hony ki nishaani hy.

(is the quality of a married male.)

\section{Analysis}

In this joke SO is angry/ polite person and the additional SO of this joke is married/ unmarried person. Incongruity of the SO is resolved by using the logical mechanism (LM) of exaggeration in which it is presented that males become habitual of gulping the anger after marriage and their wives make them suppressed while in the first sentence male's superior nature is reflected in his ability to get angry on little things. Situation (SI) is not clearly mentioned. Target of the joke are the wives who are considered to be the oppressors of their husbands. This joke is in the form of a simple narrative. Language of the joke is also simple and adjective of "married male" is used in the punch line of the joke which is the source of humor in the joke. This adjective seems to snatch every liberty from the males which helps to create exaggerate the facts regarding wives.

\section{Joke: 02}

Kuch aisay sawaal hoty hain jo insaan (mard) ko saari umer ka gulaam banadaity hain.

(There are some questions which make a man slave for the whole life.)

Jaisa k... quboolhy? Quboolhy? Quboolhy?

(As.... Accepted?.. Accepted?...Accepted?...(matrimonial words)) 


\section{Analysis}

$\mathrm{SO}$ in this joke is authoritative/unauthoritative woman and the additional SO is free/slave person. Incongruity which is introduced in SO is resolved in the logical mechanism (LM) of faulty reasoning which describes that three questions of marriage (Accepted? Accepted? Accepted?) makes a man slave for his whole life. Technique of exaggeration is used to create humor. Situation (SI) is not mentioned clearly perhaps it is the form of a speech which is presented by a person. Target of the joke are women who are considered as authoritative who make their husbands their slaves for the entire life and snatch their liberty. This particular joke has a simple narrative in the form of declaration. Second line is the punch line which is in the form of questions that generate humor.

\section{Joke: 03}

Aik sahib dusray say: Bhai khushi kya hoti hy?

(One person to the other: Brother what is happiness?)

Dusray sahib: pata nahi bhai, meri tou kam umeri ma hi shadi hogai thi.

(The other person: I don’t know brother, I got married in very early age.)

\section{Analysis}

This joke has the SO of married/unmarried person and the additional SO are authoritative/unauthoritative wives. Incongruity introduced in SO, is resolved by using LM of inferring consequences and faulty reasoning. Exaggeration is also made through which it is presented that owing to getting married in very early age a person doesn't know what happiness is because he didn't find even a moment of happiness in his married life and due to this early marriage he can't recall moments of happiness of his life before marriage. Situation (SI) in this particular joke is that two people are indulged in a dialogue in which one person is asking about happiness from other person. Target or butt of the joke are the wives who are considered violent and authoritative, who leave no space for their husbands to find happiness. Narrative of this joke is in the form of a dialogue in the question answer format and its language is simple.

\section{Joke: 04}

Shohar: Cricket wala channel lagao

(Husband: Tune cricket's channel)

Bivi: Nahi lagaongi

(Wife: No I won't)

Shohar: Daikh lounga

(Husband: I will see) 
Bivi: Kya daikh lo gy?

(Wife: What will you see?)

Shohar: Yahi channel jo tum daikh rahi ho...

(Husband: The same channel you are watching..)

\section{Analysis}

In this particular joke $\mathrm{SO}$ is Authoritative/Unauthoritative wives and its additional SO is harmless/dangerous wives. Incongruity of the joke is resolved through logical mechanism of exaggeration as the wife is presented as so authoritative that the husband is unable to make his wish of watching his favourite channel, fulfilled in the presence of his wife and his desires has no value before his authoritative wife. First he tries to behave authoritatively but the violent attitude of his wife made him lick his own words. SI of the joke is that husband and wife are sitting before TV. The favourite channel of his wife is tuned on it while the husband is trying to make his wife tune his favourite channel. This joke is in the form of a simple narrative that is in the form of a dialogue between husband and wife. Last sentence that is uttered by the husband is the punch line that humorously depicts the helplessness and pathetic condition of the husband, and his weak position at home.

\section{Wife, a Stupid Creature}

Following jokes describe that women are stupid and dumb and they don't have intellect. They are unable to make rationalize decisions. Their intelligence is discussed in these jokes.

\section{Joke: 01}

Mian bivi raat ko dair say ghar aaye. Shohar ny torch light pakri aur bivi ghar kay darwazy ka lock kholny lagi. Boht koshish kay baad bhi wo lock na kholsaki. Shohar nay torch light bivi ko pakrai aur khud lock kholny ki koshish karny lga. Lock foran khul gya tou bivi boli, "dykha... aisay pakarty hain light."

(Husband and wife came to the house late at night. Husband held the torch light and the wife started to unlock the door. Even after so much struggle she couldn't unlock the door. Husband made his wife hold the light and he himself started to unlock the door. The door opened at once and the wife uttered, look... this is how we should handle the light.) 


\section{Analysis}

Script opposition of this joke is stupid/intelligent wives and additionally created $\mathrm{SO}$ is in this joke is productive/non productive wives. Incongruity created in the script opposition is resolved through LM of exaggeration. It declares that wives are non productive for the practical works. Situation of the joke is that a man with his wife is coming back home late at night and they try to open the locked door one by one and are also indulging in a dialogue. Wives are the target of this joke as is declared in its SC that wives are stupid and non productive. Narrative of this joke is having a simple language and final or the punch line of the joke is in the form of dialogue that brings humor to the narrative of the joke. Last line is creating stereotypes about wives that they are unintelligent and stupid.

\section{Joke: 02}

Bivi apnay shohar say: Ap ko meri khoobsurti zayada achi lagti hy ya aqalmandi? (Wife to her husband: What do you like the most, my beauty or my intelligence?)

Shohar: Mujhy tou tumhari ye mazaaq ki aadat bohat achi lagti hy. (Husband: I like your this very habit of making jokes.)

\section{Analysis}

$\mathrm{SO}$ in this joke is sensible/stupid wives while additional SO of the joke are intelligent/unintelligent and beautiful/ugly wives who are usually disliked by their husbands. Incongruity which is introduced in SO is resolved by using pun in the second line of the joke to create humor as the husband considers the thought of beauty and intelligence of his wife, a joke. Exaggeration is also used as LM in the joke. Although SI is not mentioned clearly yet it can be assumed that husband and wife are in their house and talking to one another in a casual manner. Perhaps wife is trying to kill her boredom and trying to attract the attention of her husband. Target of the joke are wives as they are considered neither attractive nor intelligent by their husbands. Narrative of this joke is in the form of a dialogue in the question answer format. Language of the joke is simple. Pun used in the second line makes it a punch line and source of humor in the joke.

\section{Joke: 03}

Bivi hide and seek khailty huay: Agar apny mujhy dhoond liya tou aap mujhy shopping karwaingy.

(Playing hide and seek, wife: If you find me, you will take me to the shopping.)

Mian: Aur agar main na dhoond saka tou?

(Husband: And if I would not be able to find you?)

Bivi: Aisay tou na kahain na. Main darwazy kay peechay hi chupoongi.

(Wife: Don't say that. I will hide myself right after the door.) 


\section{Analysis}

$\mathrm{SO}$ in this joke is intelligent/stupid woman and the additional SO is extravagant/ sensible woman. Incongruity introduced in $\mathrm{SO}$ is resolved in the LM of exaggeration. LM also gives an idea of inferring consequences. SI in this joke is that a husband and a wife are playing hide and seek most probably at their home. Target or butt of the joke is a woman who is considered a stupid creature. Narrative of this joke is simple and in the form of a dialogue. First sentence is conditional, starts with "if" while second statement is a question which is answered in the third and the last statement which is a punch line and provides humor.

\section{Joke: 04}

Bivi: Tum sotay huway mujhy gaalian dy rahy thay.

(Wife: You were abusing me while sleeping.)

Shohar: Tumhain galat fehmi hui hy.

(Husband: You misunderstood.)

Bivi: Kesi galat fehmi?

(Wife: What kind of misunderstanding?)

Shohar: Yahi k .......... "main so raha tha."

(Husband: That.. "I was sleeping".)

\section{Analysis}

SO in this joke is intelligent/unintelligent wives and additionally SO of factual/nonfactual also exists in this discussed joke. LM in this joke works through exaggeration. Situation of the joke is that a wife is talking to his husband in the morning about his act of abusing her while sleeping. Butt of the joke are wives who are considered as unintelligent and dumb creatures. Narrative of the joke is in dialogue form which also includes a question statement. The statement answering that question is creating humor in the joke as the husband uses pun to describe that he was abusing his wife when he was awake. This answered statement makes a punch line and the humor of the joke wholly depends on this very statement.

\section{Wives as Bad and Ugly Creatures:}

Wives are depicted in the jokes under this category as the ugly and bad human beings who make their husbands depressive and troubled. 


\section{Joke: 01}

Shaadi kay do din baad dulha usi beauty parlour par gya jahan uski bivi ko dulhan banaya gya tha aur parlour ki maalkin ko iPhone $\mathrm{x}$ gift kiya.

(After two days of marriage, the groom went to the same beauty parlour from where his wife was made the bride and he gifted an iPhone $\mathrm{x}$ to the (female) owner of the parlour.)

Parlour ki maalkin nay uska shukrea ada kiya aur jab khushi say dabbay ko khola tou andar say Nokia 3310 nikla aur sath kagaz par likhatha............. same feeling. (The owner of the parlour thanked him and when she opened the box joyfully, there was a Nokia 3310 (lower quality cell phone) inside the box. There was also a paper with it and the words on it were "SAME FEELING".)

\section{Analysis}

In this joke $\mathrm{SO}$ is in this joke is beautiful/ugly wives and its additional $\mathrm{SO}$ is reality/illusion and the incongruity raised in the $\mathrm{SO}$ is resolved through logical mechanism of false analogy and exaggeration that to see wives without powder or make up is as depressive as to see NOKIA 3310 inside the box of an iPhone $\mathrm{x}$. Technique of parallelism is also used in the joke. SI in this joke is that the newly married husband goes to the same parlour at which his wife was made bride and presents a gift to the owner of that parlour. Target of this joke are the wives that are considered as ugliest creatures and to see them without powder is very depressive. This joke is in simple narrative using simple language. The humor of the joke depends on the words that are written on a page placed inside the box that are" SAME FEELING".

\section{Joke: 02}

Bivi: Tum mujhy do aysi baatain bolo k aik say main khush hojaon aur dusri say mujhy gussa aajaye.

(Wife: Tell me two things from which one makes me happy while other makes me annoyed.

Shohar: 1 Tum meri zindagi ho.

(Husband: (1 You are my life.)

2 Aur.....laanat hy aysi zindagi par

(2 And..... I do curse on this life.)

\section{Analysis}

$\mathrm{SO}$ of the joke is good/bad wives and the additional script opposition of this joke is happy/sad person. Logical mechanism of false analogy and of exaggeration is used to resolve the incongruity created in the joke that wife is the life of the husband and then this statement is averted and reversed by the husband that he 
curses on this life. The situation in this joke is not clearly depicted, but it can be supposed that husband and wife are at their home and are talking to one another. This joke targets wives and presents them as cursed and bad creatures who are unbearable for their husbands. Narrative of the joke is in the form of a dialogue that contains simple language. A question answer format is displayed in the joke and the second part of the husband's answer is in the form of a pun through which humor is generated.

\section{Joke: 03}

Aik aadmi ka hont jaly huway thay. Kisi nay pucha kun bhai ye hont kesy jal gye? (One man has got his lips burnt. Somebody asked him, how did you get your lips burnt?

Aadmi nay kaha, bas bhai kya btaon. Tumhari bhabi maiky ja rahi thi usko chornay station gya tha. Bas jesy hi train nay haarn bajaya, main nay khushi ma train ka engine choom liya.

(The man said, what do I tell you brother, your sister-in-law (the man's wife) was going to her mother's house and I was going to see her off at the station. As the train whistled, I kissed the train's engine joyfully.)

\section{Analysis}

In this joke script opposition in the joke is good/bad wives and its additional $\mathrm{SO}$ is happy/sad person. Incongruity of the joke is resolved in the logical mechanism of exaggeration that a husband kisses the engine of the train out of happiness that results from his wive's leaving for her parent's home. This happiness of leaving his wife in the train made him out of his senses and in this condition he kissed the engine of the train unconsciously. The situation of the joke is that a person is talking to another person and telling him the reason of his burnt lips as he got them burnt on kissing the engine of the train. Target of the joke are the wives who are depicted as the bad and dreadful creatures who are trouble for their husbands. Narrative of this particular joke is in the form of a dialogue that consists of question and answer and the language of the joke is also simple. In the last statement, exaggeration is made to produce humor in the joke.

\section{Joke: 04}

Sadqa har tarah ki bala ko taal dyta hy (Alms can avert every kind of witches/bad spirits (danger)

Siwaye uskay jis sy apka nikaah hua ho....

(Except the one whom you are married to....) 


\section{Analysis}

Script Opposition in the joke is beautiful/ugly wives and additional SO found in the joke is good/bad wives. Incongruity of the joke is resolved through the logical mechanism of exaggeration, false reasoning and through faulty analogy as wives are declared as witches and bad spirits because of their ugliness that is mere an exaggeration and it is declared that they can't be averted even through alms. Analogy also depicts that wives are identical to the witches because of their bad and ugly nature. Situation is not explicitly found in this joke. Target of the joke are the wives as they are considered as much ugly and bad as are the witches and bad spirits. Language of the joke is simple and it consists of a simple statement which has two parts second part of which is responsible of humor in the joke. Second statement that works as a connector shows the exception and declares wives as identical to witches. This statement is responsible for humor in this particular statement.

\section{Discussion and Conclusions}

Attardo's \& Raskin's General Theory of Verbal Humor is used in this particular study to analyze different patterns of the jokes and to highlight different stereotypes working under their surface. It is discussed using this theory that how these jokes are creating and promoting stereotypes about wives in our societal structure and how attitudes of individuals, particularly women are melded through humor. Disparaging attitude towards wives are presented through jokes to create stereotypes about wives in specific while women in general. Jokes on wives show that language tools are manipulated most often perhaps by men in order to show their disrespectful attitudes toward their wives. These jokes depict wives as authoritative creatures who are troublesome for their husbands and present them as violent and stupid human beings while in some jokes wives are considered as bad and ugly creatures. This shows that wive's attitudes are exaggerated and wrongly portrayed by the men in jokes as wives in specific and women in general are showing attitudes opposite to these jokes in Pakistani society. But unfortunately these stereotypes created about wives in jokes are enjoyed by both men and women in Pakistani society under the umbrella of humor which seems depressive on the part of women because they are not considering the gravity of the situation as this kind of humor is generating and promoting disparaging attitudes towards wives in specific and women in general. They are unknowingly and indirectly laughing at themselves that is very alarming as this particular humor is tagging certain weaknesses with them and providing a direction to the society for their further exploitation and negative attitudes toward them by considering them useless. In these jokes husbands are depicted as the superior individuals physically and intellectually to their wives. 
This particular study intends to highlight the disparaging attitudes and stereotypical structures about wives under the surface structures of the selected jokes and tries to make the women and especially wives aware of this situation and to make them discourage this kind of humor that is responsible for their disrespect, instead of promoting and laughing at these jokes. Moreover, this study encourages other researches also to further analyze this grave situation and to bring awareness to the individuals so that they may avoid disrespecting others under the guise of humor.

\section{References}

Attardo, S. \& Raskin, V.(1991). Script Theory Revis(it)ed: Joke Similarity and Joke Representation Model. HUMOR: International Journal of Humor Research, vol.4:3-4, pp.293-347.

Acuña Ferreira, V. (2014). The Competitive Functions of Humours in Young Women's Gossip. Feminism o/s, 0(24), 67-94. doi:https://doi.org/10. 14198/fem.2014.24.04

Attardo, Salvatore \& Hempelmann, Christian \& Maio, Sara. (2002). Script Oppositions and Logical Mechanisms: Modeling Incongruities and their Resolutions. Humor-International Journal of Humor Research - HUMOR, vol.15. pp.3-46.

Ervin-Tripp, Susan M. \& Lampert, Martin D. (1991). The Construction of Humor. Paper Presented at the 4th International Conference on Language and Social Psychology, Santa Barbara, CA.

Ervin-Tripp, Susan \& Lampert, Martin. (1992). Gender Differences in the Construction of Humorous Talk. Conference: Proceedings of the 1992 Berkeley Women and Language Conference At: Berkeley, California

Freud, S. (1960). Jokes and their relation to the unconscious (James Strachey, Trans.). New York, NY: Norton. (Original work published 1905)

Gray, John, 1992. Men are from Mars, Women are from Venus. Harper Collins, New York, NY. 
Green, Rayna, 1977. Magnolias grow in dirt:the bawdy lore of Southern women. Southern Exposure 4, 29-33.

Jenkins, Marvalee M. (1985). What's so funny?: Joking among women. In S. Bremner, N. Caskey, \& B. Moonwoman (eds.), Proceedings of the First Berkeley Women and Language Conference. Berkeley, CA: Berkeley Women and Language Group.

Lampert, Martin D., \& Ervin-Tripp, Susan M. (1989).The interaction of gender and culture on humor production. In M. Hester (Chair), What arewomen telling us about humor? Symposium conducted at the 97th Annual Convention of the American Psychological Association, New Orleans, LA.

Lampert, Martin, Ervin-Tripp, Susan, 1998. Exploring paradigms: the study of gender and sense of humor near the end of the 20th century. In: Willibald, Ruch. (Ed.), The Sense of Humor. Mouton de Gruyter, New York, pp. 231-270.

Lew, R. (1996). An ambiguity-based theory of the linguistic verbal joke in English.A Thesis submitted to the faculty of Adam Mickiewicz University in partial fulfilment of the requirements for the degree of Doctor of Philosophy April 1996". Poznan, Poland,unpublished thesis. http://www.staff.amu.edu.pl/u rlew/

Maio, G., Olson, J. \& Bush, J. (1997).Telling Jokes That Disparage Social Groups: Effects on the Joke Teller's Stereotypes. Journal of Applied Social Psychology, vol.27:22, pp.1986-2000.

Masaeli\&Heidari-Shahreza (2016.A Linguistic Analysis of Persian Online Jokes in Light of General Theory of Verbal Humor,Journal of Applied Linguistics and Language Research,vol.3:7, pp.230-239.

Piskorska, A. (2016). Humor and Popular Stereotypes of Scots.Scottish Culture: Aniela Korziiowska, IzabelaSzymanska, Semper, pp.369-379.

Rashad, S. \&Azher, M. (2018). Women in Jokes: A Linguistic Analysis of Jokes on Pakistani Social Media in the Light of General Theory of Verbal Humor. Pakistan Journal of Women's Studies: Alam-e-Niswan vol.25:2, pp.115-132. 
Raskin, Victor \& Hempelmann, Christian \& Rayz, Julia. (2009). How to understand and assess a theory: The evolution of the SSTH into the GTVH and now into the OSTH. Journal of Literary Theory, 3. 10.1515/JLT.2009.016.

Oring, Elliott. (1992). Jokes and their Relations. Lexington, KY: University Press of Kentucky.

Zillmann, D. \& Cantor, J. R. (1976). Dispositional Theory of Humor and Mirth. In A. J. Chapman \& H. C. Foot (Eds.), Humor and Laughter: Theory, Research and Applications (pp. 93-115). London, England: John Wiley \& Sons.

Zillmann, D. (1983). Disparagement Humor. In P. E. McGhee \& J. H. Goldstein (Eds.), Handbook of Humor Research (Vol. 1, pp. 85-108). New York, NY: Springer-Verlag.

Ammara Iqbal is M.Phil Scholar in the Department of English, University of Sargodha, Sargodha, Pakistan.

Muhammad Asim Mahmood is Dean Faculty of Arts and Social Sciences, Government College University Faisalabad, Faisalabad, Pakistan.

Musarrat Azher is Lecturer in the Department of English, University of Sargodha, Sargodha, Pakistan. 